\title{
Template Adsorbent Composed of Particles Impregnated with Pre-organized Ligand through Its Metal Complexes: Uranyl Ion-Selective Adsorbents
}

\author{
Shigeki SEKI, Masashi NiSHIDA, and Isao YOSHIDA \\ Department of Applied Chemistry, Faculty of Engineering, Sojo University, Kumamoto 860-0082, Japan
}

(Received April 9, 2001; Accepted April 23, 2001)

The development of functional materials which react selectively with a target metal ion or molecule is an important theme in the field of separation chemistry. Water-soluble hydroxycalix[6]arene-p-sulfonate ion, $\mathrm{H}_{2} \mathrm{~L}_{6}{ }^{6-}\left(\mathbf{1}_{n}, n=6, \mathrm{H}_{2}\right.$ means that the ligand is a di-protonic acid) and its $O$ carboxylmethyl derivative were shown to be functional materials for $\mathrm{UO}_{2}{ }^{2+}$, that is, they are superuranophiles both in selective reactivity and high stability of the complex..,2 In the present study, the $\mathrm{UO}_{2}{ }^{2+}$-selective adsorbent was composed of a non-polar organic resin, XAD-7, and silica-gel particles loaded with an ionic associate of another superuranophile, ${ }^{3,4} \mathrm{H}_{4} \mathrm{~L}_{8}{ }^{8-}\left(\mathbf{1}_{n}\right.$, $n=8$, Fig. 1) and methyltrioctylammonium ion, $\mathrm{MTA}^{+},\left(\mathrm{MTA}^{+}\right)_{11}$ $\left(\mathrm{HL}_{8}{ }^{11-}\right)$. They were prepared by first impregnating the $\mathrm{MTA}^{+}$ associate of a $\mathrm{UO}_{2}{ }^{2+}-\mathrm{H}_{4} \mathrm{~L}_{8}{ }^{8-}$ complex, ${ }^{5}$ then stripping $\mathrm{UO}_{2}{ }^{2+}$ using $0.5 \mathrm{M}\left(1 \mathrm{M}=1 \mathrm{~mol} \mathrm{~L}^{-1}\right)$ sulfuric acid. It was found that they have an evident template effect in the adsorption of $\mathrm{UO}_{2}{ }^{2+}$, in comparison with those loaded with a $\mathrm{H}_{4} \mathrm{~L}_{8}{ }^{8-}-\mathrm{MTA}^{+}$associate prepared in the absence of $\mathrm{UO}_{2}{ }^{2+}$ and in the presence of $\mathrm{Ti}^{4+}$.

Forty milliliters of a mixture solution containing $1.0 \mathrm{mmol}$ of $\mathrm{Na}_{8} \mathrm{H}_{4} \mathrm{~L}_{8}$ and $2.0 \mathrm{mmol}$ of $\mathrm{UO}_{2}\left(\mathrm{NO}_{3}\right)_{2}$ were taken into a $100 \mathrm{~mL}$ separating funnel. Then, $40 \mathrm{~mL}$ of a chloroform solution containing $12 \mathrm{mmol}$ of $\mathrm{MTA}^{+} \mathrm{Cl}^{-}$was added to the funnel. By shaking at 200 strokes/min for $10 \mathrm{~min}$, the $\mathrm{MTA}^{+}$associate with a $\mathrm{UO}_{2}^{2+}-\mathrm{H}_{4} \mathrm{~L}_{8}^{8-}$ complex, $\left(\mathrm{MTA}^{+}\right)_{11}\left(\mathrm{UO}_{2}\right)_{2} \quad\left(\mathrm{H}_{-3} \mathrm{~L}_{8}{ }^{15-}\right)$, was extracted at $\mathrm{pH} 8.0 .^{6}$ After separating the chloroform phase, 10 $\mathrm{g}$ of Amberlite XAD-7 (R) or $30 \mathrm{~g}$ of silica gel (S, Wako gelC100) particles was added. Chloroform was then evaporated off by heating at $40^{\circ} \mathrm{C}$. Another complex-type adsorbent, having particles loaded with an $\mathrm{MTA}^{+}$associate of $\mathrm{Ti}^{4+}-\mathrm{H}_{4} \mathrm{~L}_{8}^{8-}$ complex was also prepared by similar procedures in the presence of $\mathrm{Ti}^{4+}$ at $\mathrm{pH} 3.0$, instead of $\mathrm{UO}_{2}{ }^{2+}$. The ligand-type adsorbents, in which an $\mathrm{MTA}^{+}$associate of $\mathrm{H}_{4} \mathrm{~L}_{8}{ }^{8-}$, $\left(\mathrm{MTA}^{+}\right)_{11}$ $\left(\mathrm{HL}_{8}{ }^{11-}\right),{ }^{7}$ is loaded on the particles, (L)MTAL8-R and (L)MTAL8-S, were prepared using similar procedures in the absence of metal ions. The complex-type adsorbents were packed into a glass column of $1.5 \mathrm{~cm}$ i.d. and treated with 200

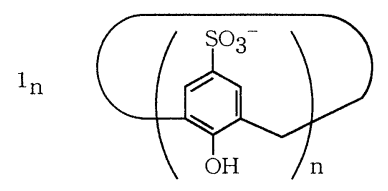

Fig. 1 Chemical structure of water-soluble hydroxycalix $[n]$ arene- $p$ sulfonate ion.

\footnotetext{
† To whom correspondence should be addressed.

E-mail: yoshida@chem.sojo-u.ac.jp
}

$\mathrm{mL}$ of $0.5 \mathrm{M}$ (for $\mathrm{UO}_{2}^{2+}$ ) or $2.5 \mathrm{M}$ sulfuric acid (for $\mathrm{Ti}^{4+}$ ) in order to remove metal ions. After washing the column with 100 $\mathrm{mL}$ of deionized water, the particles were air-dried, and used as complex-type adsorbents: (U)MTAL8-R, (U)MTAL8-S, (Ti)MTAL8-R and (Ti)MTAL8-S.

The extent of impregnation was measured by gravimetry after recovering the associate with chloroform and then evaporating. A part of the eluate was taken in a separation funnel and back extracted with $2 \mathrm{M}$ hydrochloric acid. The amount of the ligand was measured by spectrophotometry at $289 \mathrm{~nm}$ in an aqueous solution of $\mathrm{pH} \mathrm{13.0.}{ }^{6}$

The adsorption of $\mathrm{UO}_{2}{ }^{2+}$ by the batch-wise method was carried out as follows. Into a $50 \mathrm{~mL}$ Erlenmeyer flask, $0.1 \mathrm{~g}$ (XAD-7) or $0.3 \mathrm{~g}$ (silica gel) of adsorbent was taken; then, 25 $\mathrm{mL}$ of the $\mathrm{UO}_{2}{ }^{2+}$ solution containing sodium hydrogen carbonate of a desired $\mathrm{pH}$ was added. The reaction was performed for a given time under mild and occasional mixing; then, an aliquot of the aqueous phase was taken, and its $\mathrm{UO}_{2}{ }^{2+}$ concentration, $C$, was determined by the Arsenazo-III method. ${ }^{8}$ The adsorption capacity, $Q$, was calculated according to $Q=\left(C_{0}\right.$ $-C) \times 25 / w$ mmol g-1, where $w$ and $C_{0}$ denote the weight of the adsorbent used and the initial concentration of $\mathrm{UO}_{2}{ }^{2+}$ in the aqueous phase, respectively. The percent adsorption and the distribution ratio, $D$, were obtained from $\left(C_{0}-C\right) / C_{0} \times 100 \%$ and from $Q / C \mathrm{~mL} \mathrm{~g}^{-1}$, respectively. The saturated adsorption capacity, $Q_{\infty}$, was obtained from another adsorption experiment performed for $48 \mathrm{~h}$ in a solution containing an excess amount of $\mathrm{UO}_{2}{ }^{2+}$.

The results are summarized in Table 1. The amount of impregnated associate was $34.9-38.2 \%$ for XAD-7 and about $17 \%$ for each silica gel particle, indicating that the amount of associate impregnated differed with the kind of support, but not with the ligand- and complex-type. The appearances of each adsorbent such as color, size and rough feel of a particle, were similar to each other both before and after impregnation. Loading greater amounts than those given in Table 1, however, caused over-loading and sticky particles. Similar amounts of $\mathrm{H}_{4} \mathrm{~L}_{8}^{8-}$, such as $0.107-0.0861 \mathrm{mmol} \mathrm{g}^{-1}$ for XAD-7 and about $0.033 \mathrm{mmol} \mathrm{g}^{-1}$ for silica-gel particles, were also found in accordance with the amount of ionic associate impregnated, irrespective of the ligand- and complex-type. These adsorbents were stable and no release of the ionic associates was observed in water.

The $\log D$ values and \% adsorption given in Table 1 are distinctly larger in the order (U)MTAL8-R $\geqq(T i) M T A L 8-R$ > (L)MTAL8-R and (U)MTAL8-S > (Ti)MTAL8-S > (L)MTAL8-S, respectively, for the XAD-7 and silica geladsorbents. These facts clearly indicate that the complex-type adsorbents are stronger than the ligand-type, and that in the 
Table 1 Concentrations of ionic associate and $\mathrm{H}_{4} \mathrm{~L}_{8}{ }^{8-}$ of each adsorbent, and their \% adsorption, $\log$ distribution ratio, $\log D$, adsorption capacity, $Q_{\infty}$, and $Q_{\infty} /\left[\mathrm{H}_{4} \mathrm{~L}_{8}{ }^{8-}\right]$ for $\mathrm{UO}_{2}{ }^{2+}$ at $\mathrm{pH} 7.5 \pm 0.2$ and about $25^{\circ} \mathrm{C}$

\begin{tabular}{ccccccc}
\hline \multicolumn{1}{c}{ Adsorbent } & $\mathrm{MTA}^{+}-\mathrm{H}_{4} \mathrm{~L}_{8}{ }^{8-}, \%$ & $\mathrm{H}_{4} \mathrm{~L}_{8}^{8-} / \mathrm{mmol} \mathrm{g}^{-1}$ & $\%$ adsorption & $\log D^{\mathrm{b}}$ & $Q_{\infty} / \mathrm{mmol} \mathrm{g}^{-1}$ & $Q_{\infty} /\left[\mathrm{H}_{4} \mathrm{~L}_{8}^{8-}\right]$ \\
\hline (U)MTAL8-R & 38.2 & 0.107 & 99.5 & $4.70(64.6)$ & 0.218 & 2.04 \\
(Ti)MTAL8-R & 35.4 & 0.0957 & 93.7 & $3.57(4.79)$ & 0.171 & 1.79 \\
(L)MTAL8-R & 34.9 & 0.0861 & 75.5 & $2.89(1.00)$ & 0.151 & 1.75 \\
(U)MTAL8-S & 17.0 & 0.0332 & 99.0 & $4.39(20.9)$ & 0.0704 & 2.12 \\
(Ti)MTAL8-S & 16.9 & 0.0329 & 97.4 & $3.97(7.94)$ & 0.0670 & 2.04 \\
(L)MTAL8-S & 16.6 & 0.0330 & 82.4 & $3.07(1.00)$ & 0.0399 & 1.21 \\
\hline
\end{tabular}

a. Reaction time $=48$ h. b. $\%$ adsorption and $\log D$ obtained using $0.1 \mathrm{~g}$ of XAD-7 (R) and $0.3 \mathrm{~g}$ of silica gel (S) adsorbents in $25 \mathrm{~mL}$ aqueous solution containing $2.5 \times 10^{-3} \mathrm{mmol}_{\text {of }} \mathrm{UO}_{2}{ }^{2+}$. The values in parenthesis are relative $D$ values based on ligand type adsorbent for each matrix.

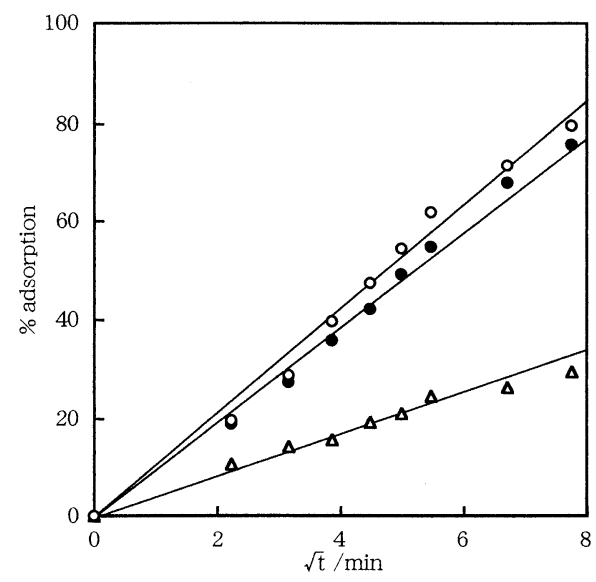

Fig. 2 Effect of the reaction time on the \% adsorption of $\mathrm{UO}_{2}^{2+}$ by silica-gel adsorbents, ((U)MTAL8-S( o), (Ti)MTAL8-S(•) and $(\mathrm{L}) \mathrm{MTAL} 8 \mathrm{~S}(\triangle)$ at room temperature $\left(\right.$ about $\left.25^{\circ} \mathrm{C}\right)$ ). Adsorbent $=$ $0.20 \mathrm{~g}, \mathrm{H}_{2} \mathrm{O}=50 \mathrm{~mL},\left[\mathrm{UO}_{2}{ }^{2+}\right]_{0}=1.00 \times 10^{-4} \mathrm{M},\left[\mathrm{NaHCO}_{3}\right]=5.00 \times$ $10^{-4} \mathrm{M}, \mathrm{pH}=7.5 \pm 0.2$.

complex types the $\mathrm{UO}_{2}{ }^{2+}$ type is stronger than the $\mathrm{Ti}^{4+}$ type in adsorptivity for $\mathrm{UO}_{2}{ }^{2+}$. The values for $Q_{\infty}$ of the complex-type adsorbents are also larger than those by the ligand-type. The value of the ratio $Q_{\infty} /\left[\mathrm{H}_{4} \mathrm{~L}_{8}{ }^{8-}\right]$, that is, the number of active sites of the ligand in the associate, was $2.00 \pm 0.14$ for four kinds of complex-type, and 1.75 and 1.21 for two ligand-type adsorbents. This may show that the chelating ability of $\mathrm{H}_{4} \mathrm{~L}_{8}{ }^{8-}$ is fully working for $\mathrm{UO}_{2}{ }^{2+}$, even in the solid phase of the complex-type adsorbents, as in the aqueous solution, ${ }^{3}$ but not in the ligand-type adsorbents.

In addition to the above facts, it was also found that the adsorption rates of these adsorbents for $\mathrm{UO}_{2}^{2+}$, which were measured in terms of the change of $\%$ adsorption with the reaction time in the initial stage of adsorption, were in the order (U)MTAL8-R > (U)MTAL8-S > (Ti)MTAL8-R > (Ti)MTAL8$\mathrm{S} \gg$ (L)MTAL8-S. The results for silica-gel adsorbents are shown in Fig 2. These facts suggest that much of the $\mathrm{H}_{4} \mathrm{~L}_{8}{ }^{8-}$ in the complex-type adsorbents is kept in a pre-organized "cone" structure (Fig. 3, A), which is more favorable to bind $\mathrm{UO}_{2}{ }^{2+}$. On the other hand, in the ligand-type adsorbent, much of the ligand must be kept in "alternate" (Fig. 3, B) or "double partial cone" structures, which are unfavorable for picking up $\mathrm{UO}_{2}{ }^{2+}$ unless their conformations change to a "cone" structure. The presence of such structures is shown for the more rigid hexamer homologue, $\mathrm{H}_{2} \mathrm{~L}_{6}{ }^{6-}$, even in aqueous solution. ${ }^{9}$

It has been reported that there was no template effect in the ligand-impregnated adsorbents which were prepared by encapsulating metal complexes followed by stripping the metal

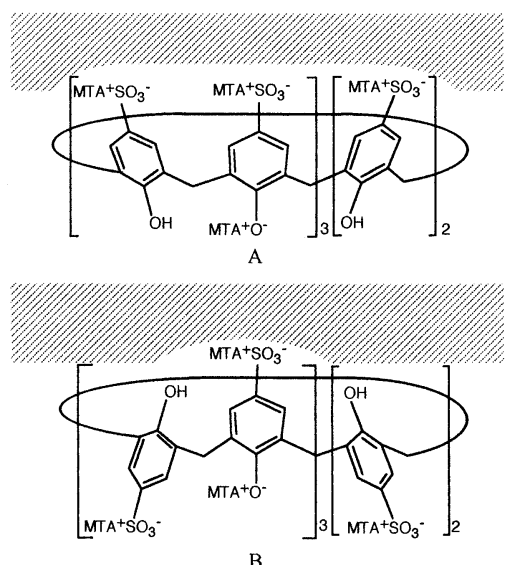

Fig. 3 "cone" (A) and an "alternate" (B) structures for the ionic associate of $\mathrm{MTA}^{+}$and $\mathrm{H}_{4} \mathrm{~L}_{8}{ }^{8-},\left(\mathrm{MTA}^{+}\right)_{11}\left(\mathrm{HL}_{8}{ }^{11-}\right)$, in the complex and ligand-type adsorbents.

ion. ${ }^{10,11}$ Thus, it can be concluded that the ligand-impregnated adsorbent, having the best conformation for binding $\mathrm{UO}_{2}{ }^{2+}$, is the first prepared template adsorbent for the adsorption of $\mathrm{UO}_{2}{ }^{2+}$.

\section{References}

1. S. Shinkai, H. Koreishi, K. Ueda, and O. Manabe, J. Chem. Soc., Chem. Commun., 1986, 233.

2. S. Shinkai, H. Koreishi, K. Ueda, T. Arimura, and O. Manabe, J. Am. Chem. Soc., 1987, 109, 6371.

3. M. Sonoda, H. Hayashi, M. Nishida, D. Ishii, and I. Yoshida, Anal. Sci., 1998, 14, 493.

4. M. Sonoda, M. Nishida, D. Ishii, and I. Yoshida, Anal. Sci., 1999, 15, 1207.

5. M. Nishida, M. Sonoda, D. Ishii, and I. Yoshida, Chem. Lett., 1999, 1275.

6. M. Nishida, H. Kondo, M. Sonoda, D. Ishii, and I. Yoshida, Bull. Chem. Soc. Jpn., 2000, 73, 1823.

7. M. Nishida, M. Sonoda, D. Ishii, and I. Yoshida, Bull. Chem. Soc. Jpn., 1998, 71, 2845.

8. H. Ohnishi and Y. Toita, Bunseki Kagaku, 1969, 18, 592.

9. J. L. Atwood, D. L. Clark, R. K. Juneja, G. W. Orr, K. D. Robinson, and R. L. Vincent, J. Am. Chem. Soc., 1992, $114,7558$.

10. J. L. Cortina and A. Warshawsky, in "Ion Exchange and Solvent Extraction", ed. J. A. Marinsky and Y. Marcus, 1997, Chap. 5, Marcel Dekker, New York, 201.

11. K. Yoshizuka, Y. Sakamoto, Y. Baba, and K. Inoue, Hydrometallurgy, 1990, 23, 309. 